\title{
Transitional-tensile fracture propagation: a status report
}

\author{
T. Engelder \\ Department of Geosciences, The Pennsylvania State University, University Park, PA 16802, USA
}

Received 17 August 1998; accepted 13 January 1999

\begin{abstract}
One model for the development of hybrid shear fractures is transitional-tensile fracture propagation, a process described as the in-plane propagation of a crack subject to a shear traction while held open by a tensile normal stress. Presumably, such propagation leads to a brittle structure that is the hybrid of a joint and a shear fracture. Crack-seal veins with oblique fibers are possible candidates. While these veins clearly show shear offset, this is not conclusive evidence that a shear traction was present at the time of initial crack propagation. Many recent structural geology textbooks use a parabolic Coulomb-Mohr failure envelope to explain the mechanics of transitional-tensile fracturing. However, the laboratory experiments cited as demonstrating transitional-tensile behavior fail to produce the fracture orientation predicted by a parabolic failure envelope. Additional attempts at verification include field examples of conjugate joint sets with small acute angles, but these conjugate joints form neither simultaneously nor in the stress field required by the transitional-tensile model. Finally, linear elastic fracture mechanics provides strong theoretical grounds for rejecting the notion that individual cracks propagate in their own plane when subject to a shear traction. These observations suggest that transitional-tensile fracture propagation is unlikely to occur in homogeneous, isotropic rock, and that it is not explained by a parabolic Coulomb-Mohr failure envelope as several recent structural geology textbooks have suggested. (C) 1999 Elsevier Science Ltd. All rights reserved.
\end{abstract}

\section{Introduction}

Most structural geologists recognize two types of brittle fractures: joints and shear fractures. A common perception promulgated in many recent structural geology textbooks is that joints and shear fractures are the end members of a spectrum of brittle fracture types, and that some fractures are a hybrid of both end members (cf. Hancock, 1985). Such fractures presumably open as tensile cracks and simultaneously propagate in the same plane while subject to a shear traction. As an example, Price and Cosgrove (1990) show a vein for which "it is clear that the planar fracture developed in hybrid extension and shear failure" (Fig. 1). Similar fractures are known by a variety of names: oblique shear fractures (Dennis, 1972), hybrid shear fractures, conjugate hybrid joints, conjugate shear joints (Hancock, 1985), joints formed in the transitional tensile field (Suppe, 1985), hybrid shear/dila-

E-mail address: engelder@geosc.psu.edu (T. Engelder) tional fractures (Price and Cosgrove, 1990), hybrid members or hybrid joints (Bahat, 1991), mixed-mode fractures (Twiss and Moores, 1992), fractures that are a combination of extension and shear (Davis and Reynolds, 1996), and transitional-tensile fractures (van der Pluijm and Marshak, 1997). van der Pluijm and Marshak (1997) noted that "Most fracture specialists claim that transitional-tensile fractures do not occur in nature, and point out that no experiments have yet clearly produced transitional-tensile fractures in the lab." The purpose of this short paper is to amplify on their comment about transitional-tensile fracture propagation and to move the structural geology community toward a clearer understanding of the nature of hybrid shear fracturing.

The hybrid shear fracture hypothesis has its origin more than a half century ago when engineers observed that the Coulomb-Mohr failure envelope was concave to the normal stress axis (Leon, 1934). Laboratory tests confirm this behavior for rocks subject to compressive stresses (Fig. 2). Furthermore, a parabolic fail- 


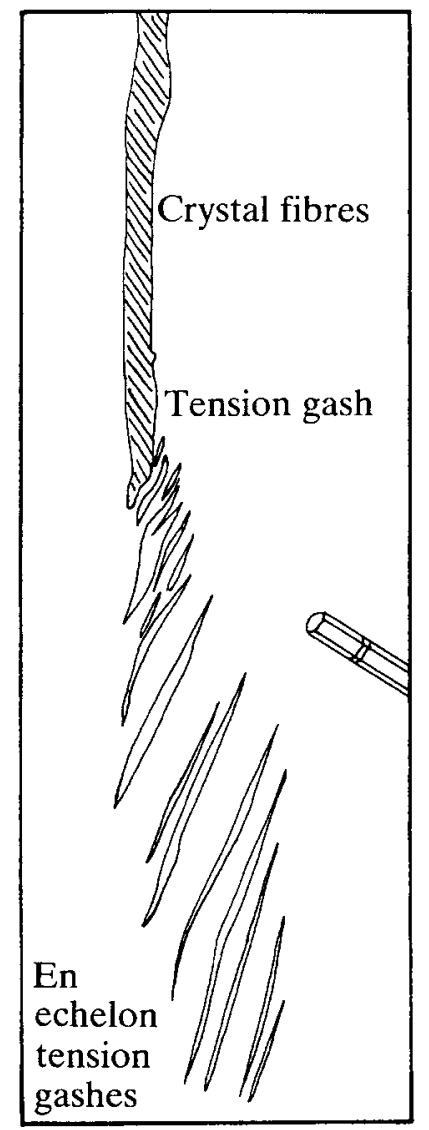

Fig. 1. A sketch of a vein with oblique fibers that Price and Cosgrove (1990, their fig. 1.63) offer as an example of hybrid extension and shear fracture, running laterally into a shear zone. The eraser head of a pencil is shown for scale.

ure envelope and its extension into the tensile field of the Mohr diagram are the natural consequence of the criterion for shear failure as derived by Griffith (1924):

$\left(\sigma_{1}-\sigma_{3}\right)^{2}=8 T_{0}\left(\sigma_{1}+\sigma_{3}\right)$

where $T_{0}$ is the uniaxial tensile strength of a rock and $\sigma_{i}$ are the principal stresses (for a more complete derivation see Murrell, 1958; Jaeger and Cook, 1969, p. 95). By 1950, engineers presumed that the CoulombMohr failure envelope could be extended above the tensile portion of the normal-stress axis to intersect that axis (Nadai, 1950). Later in this same period, Brace (1960) warns that, "A common misconception is that the Griffith theory predicts the orientation ${ }^{1}$ of the macroscopic fracture...It does not predict how the critical crack will propagate". I interpret 'how' to refer to the propagation path of the critical crack once propagation is initiated. Brace (1960) is telling the geo-

\footnotetext{
${ }^{1}$ The orientation of the fracture is customarily measured as the angle, $\theta$, between $\sigma_{1}$ and the plane of the fracture (author annotation).
}

logical community that the Griffith equation is not useful for understanding transitional-tensile behavior.

The issue, of course, is whether drawing the parabolic envelope into the tensile portion of the Mohr diagram is a legitimate representation of the fracture propagation process. This presents a challenge because the tensile portion of the Mohr diagram is extraordinarily difficult to investigate with experimental techniques. Handin and Hager (1957) and Price (1958) offer implicit opinions on the behavior of internal friction for clastic rocks subject to at least one component of tensile stress (Fig. 2). At the time, scientists hoped that the curved Coulomb-Mohr failure envelope would provide a unified failure criterion that encompassed both jointing and shear fracturing (Muehlberger, 1961). The intersection point on the normal-stress axis was defined by the tensile strength of a rock and served as the failure criterion leading to joint propagation. Most modern structural geology textbooks, even those that do not explicitly discuss transitional-tensile fracturing (e.g. Hobbs et al., 1976; Hatcher, 1990), draw the Coulomb-Mohr envelope as a concave line crossing into the tensile normal-stress field and intersecting the normal-stress axis as if it had a strong physical connection to the orientation of brittle fracture propagation under transitional-tensile stress conditions.

\section{Transitional-tensile fracture propagation}

Structural geologists and geological engineers have traditionally looked to four sources for verification and understanding of structures: the laboratory, the field, petrofabrics, and theory. In general, present understanding of transitional-tensile fracture propagation is based on the empirical Coulomb-Mohr envelope. Specifically, present geological doctrine holds that the parabolic envelope stemming from Griffith's equation [Eq. (1); Griffith, 1924] is a valid failure criterion in the tensile normal-stress field of the Mohr diagram. An auxiliary notion is that the $2 \theta$ angle defined by the intersection of the Mohr circle and the Coulomb-Mohr failure envelope predicts the orientation of transitional-tensile fracture propagation. For laboratory verification of transitional-tensile fracture propagation, Hobbs et al. (1976), Paterson (1978), Hoek and Bray (1981), and Suppe (1985) all point to a series of extension experiments by Brace (1964). Because the empirical verification of transitional-tensile fracturing depends on this single suite of experiments, it is worthwhile to review Brace's results.

The Brace experiments were axial extension tests using a dog-bone-shaped sample with a thin waist and thick ends, which allows for the generation of an axial tension while the sample is subject to a confining 


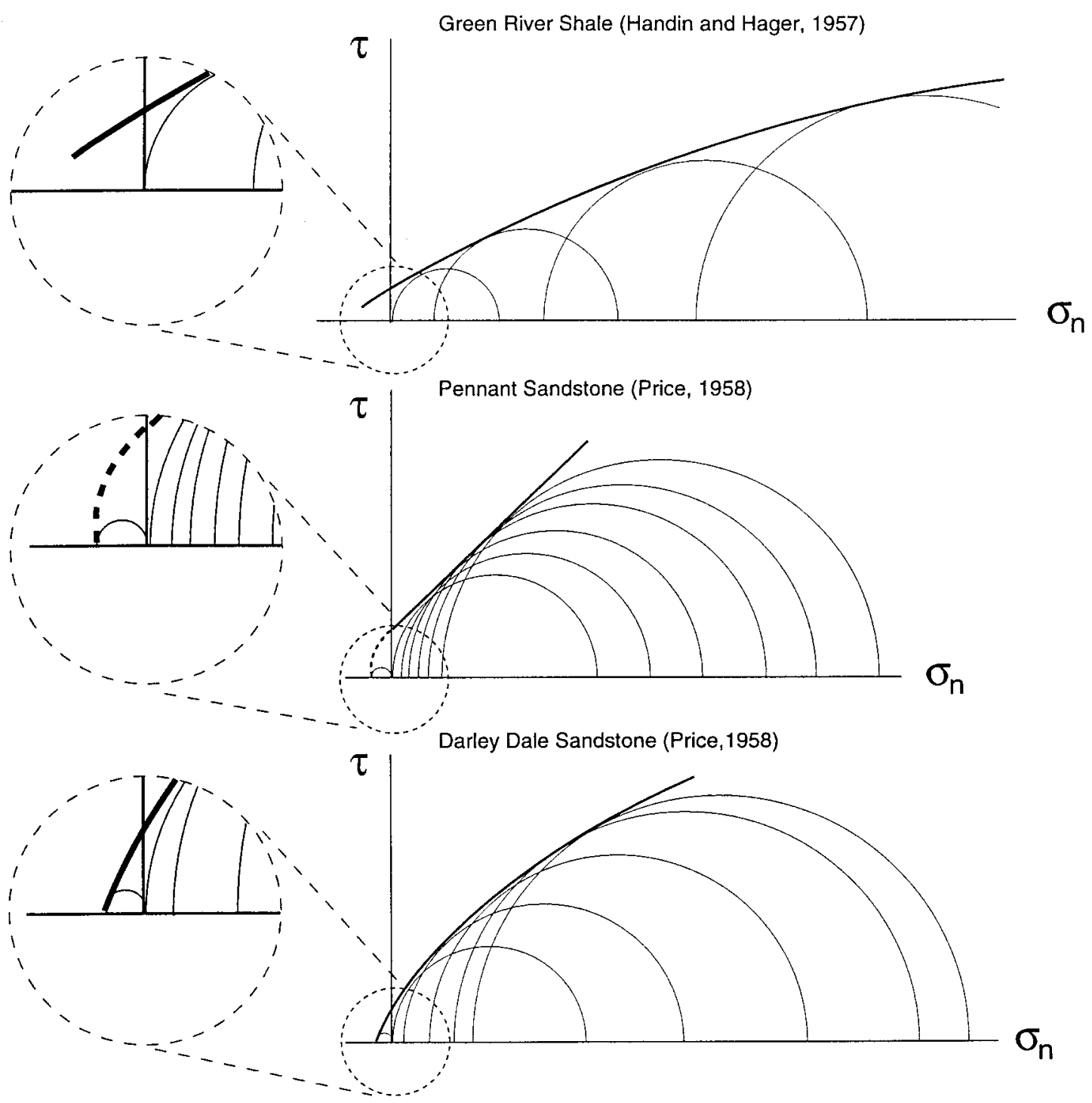

Fig. 2. Three examples of Coulomb-Mohr failure envelopes as redrawn from Handin and Hager (1957) for the Green River Shale, and from Price (1958) for the Pennant and Darley Dale sandstones.

pressure. Granite, quartzite, diabase, and two dolomites were tested, with two to four samples of each specimen subjected to an axial tension at failure while under a confining pressure (a total of 15 experiments ${ }^{2}$ ). Six of these samples fractured at a tensile stress significantly less than the predicted uniaxial tensile strength (i.e. stress conditions under which transitional-tensile fracture propagation or at least hybrid shear fracturing should have occurred). Three of these six samples failed normal to the direction of axial tension (i.e. the fracture was a common joint), and the other three failed on surfaces whose normals were $4^{\circ}, 5^{\circ}$ and $6^{\circ}$

\footnotetext{
${ }^{2}$ After Bill Brace's retirement, I wrote to MIT asking to examine the suite of dog-bone samples from his 1964 paper. Sadly, I found that all the samples had been thrown out.
}

from the direction of axial tension (i.e. these failure surfaces are candidates for transitional-tensile fracture propagation). The remaining seven samples failed as common joints normal to axial tension and at axial stresses close to the uniaxial tensile strength of the specimen.

The parabolic Coulomb-Mohr failure envelope is a reasonable predictor of fracture angles in samples that fail under compression (i.e. axial shortening tests; e.g. Handin, 1969). This success, coupled with the transformation of the Griffith equation to a parabolic failure envelope, gave structural geologists hope that the projection of the failure envelope into the tensile portion of the normal stress field had physical significance when it came to predicting fracture orientation during transitional-tensile behavior (e.g. Muehlberger, 1961). However, as Brace (1964) shows, the theoretical failure 


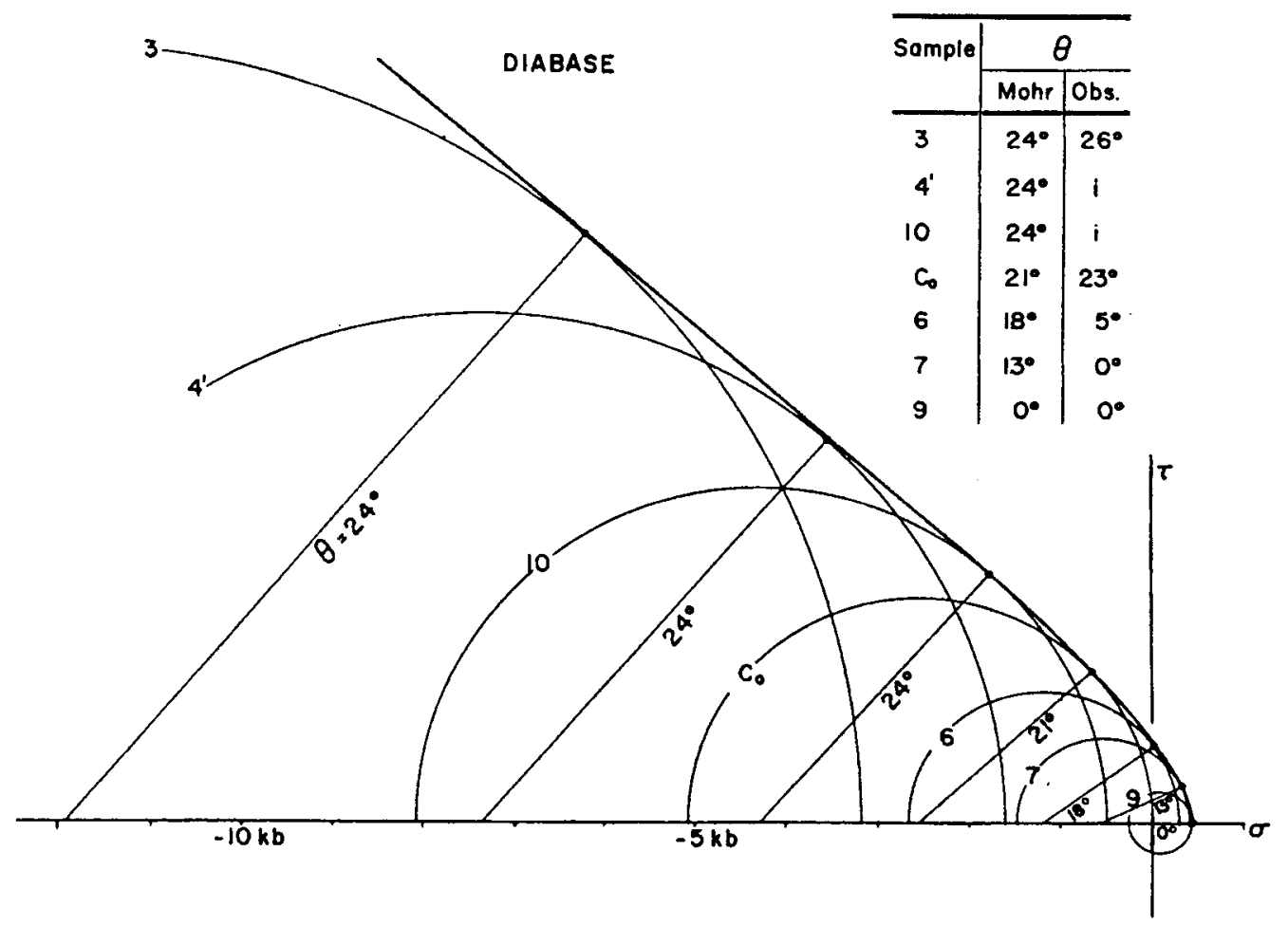

Fig. 3. The Coulomb-Mohr failure envelope for diabase drawn from seven experiments at various confining pressures (adapted from Brace, 1964). Experiments 6 and 7 were subjected to stresses that should have produced transitional-tensile fracture propagation. Fracture angles of $18^{\circ}$ and $13^{\circ}$ were predicted whereas the samples failed at angles of $5^{\circ}$ and $0^{\circ}$, respectively.

angle during transitional-tensile behavior is significantly larger $\left(\approx 13^{\circ}\right.$ for diabase) than observed in the samples subject to stress conditions favoring transitional-tensile fracture propagation (Fig. 3). In other words, Brace's laboratory tests failed to produce transitional-tensile fractures when such behavior was predicted by theory. Even if we are generous and declare that transitional-tensile behavior has occurred when any non-zero failure angle is produced [Brace (1964) did not make such a claim], the success rate is only $50 \%$, a rate that should make experimentalists skeptical.

The field evidence cited by Muehlberger (1961) as supporting transitional-tensile behavior includes the 'conjugate' joint sets described by Parker (1942) from the Appalachian Plateau, New York. This particular conjugate pattern arises from non-synchronous joint propagation (e.g. Younes and Engelder, 1999) and hence, fails to support the transitional-tensile mechanism. Dennis (1972) cites conjugate joint sets mapped by Ziony (1966) in Permian sandstone of the Monument Upwarp, Utah, as field evidence for transitional-tensile behavior. While some of the Permian sandstone beds over Comb Ridge have 'conjugate' joint sets, many cross-cut at an angle that is too large for transitional-tensile behavior (Ziony, 1966). Joint sets with angular relationships consistent with transitional-tensile fracture propagation are easy to find in the field (e.g. Hancock, 1985) but proving that they propagated simultaneously with positive wall dilation is difficult. Alternatively, field evidence for out-ofplane propagation of joints and dikes subject to a shear traction is abundant (e.g. Muller and Pollard, 1977; Olson and Pollard, 1989; Cruikshank et al., 1991). Perhaps only those joints described by Hancock (1986) as a joint spectrum remain as potential candidates for transitional-tensile behavior.

There is no doubt that many veins open with a component of shear displacement (e.g. Cox, 1987). Price and Cosgrove (1990; their fig. 2.2) show such a vein when taking issue with the definition of joints offered by Griggs and Handin (1960) as dilational features that exhibit no shear. The issue is whether a vein showing shear offset initiated as such within an isotropic, homogeneous rock, and then propagated in its own plane while that plane was subjected to a shear couple as well as an effective crack-normal tension. Unfortunately, a petrographic thin section of a vein offers no conclusive evidence that the initial crack propagation was in-plane while that plane was subjected to a shear stress. The alternative interpretation is that the shear offset reflects a reorientation of the stress field after the initial in-plane propagation, an interpretation that Price and Cosgrove (1990) accept as valid.

Another reason why crack-seal veins may not be of 


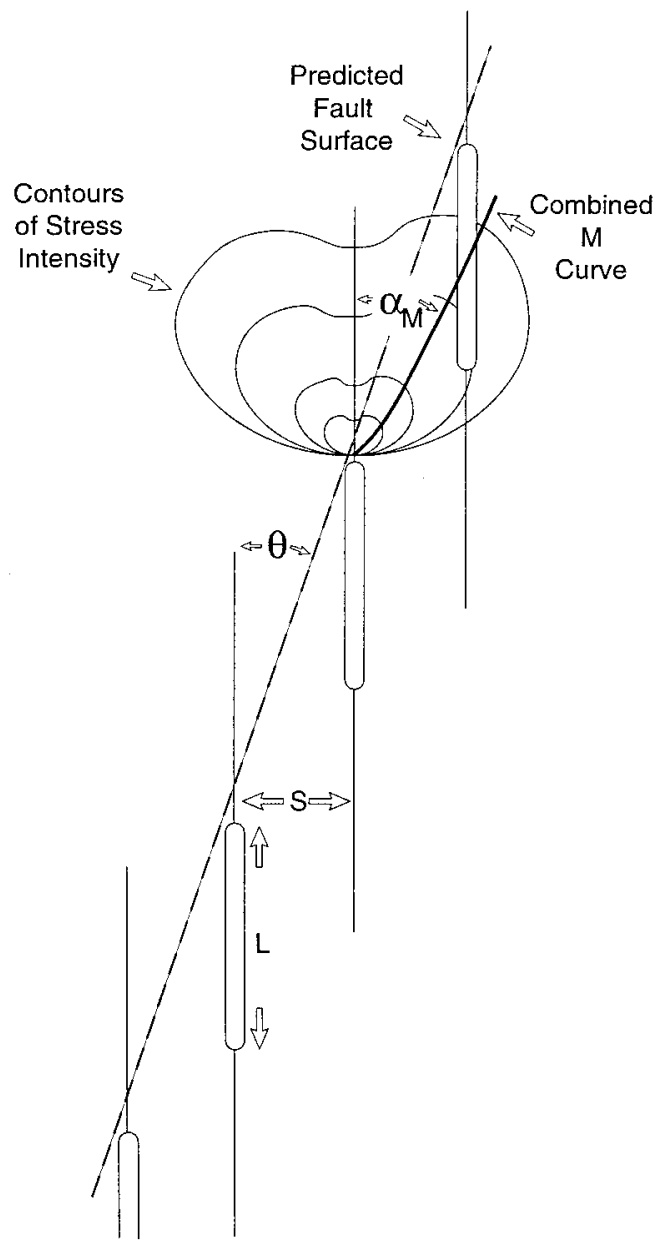

Fig. 4. The stress concentration at the tip of a crack showing contours of stress intensity near the tip (adapted from Reches and Lockner, 1994). See text for details.

a transitional-tensile origin is that each cracking event may follow the boundaries of pre-existing veins, where large fluid inclusions act as a stress guide to prevent each subsequent cracking episode from turning out-ofplane (Fisher, 1998, personal communication). In this case, transitional-tensile behavior on recracking may depend on local inhomogeneities or an anisotropy at the boundary between the vein and the country rock. This is not the sort of situation used to develop the empirical parabolic failure envelope on the Mohr diagram.

Linear elastic fracture mechanics (LEFM) is explicit in predicting crack propagation paths (e.g. Lawn, 1993), and has been successfully applied to explain the geometry of joint propagation (Pollard and Segall, 1987). LEFM predicts that a crack subjected to a shear traction, as is required for transitional-tensile behavior, does not propagate in its plane but rather curves to seek the orientation of maximum circumferential stress (Erdogan and Sih, 1963), maximum strain energy release (Hussain et al., 1974), and minimum strain energy density (Sih and MacDonald, 1974). According to the theory, shear stress on a crack increases the crack-tip stress intensity, so that less tensile normal stress is required for crack propagation (Ingraffea, 1987). It was apparently the increase in shear stress on microcracks that led to failure of several of Brace's samples (Brace, 1964) at tensile stresses less than the uniaxial tensile strength. To understand the effect of shear stress on crack propagation, Brace and Bombolakis (1963) ran a series of experiments showing that when cracks were subjected to a shear traction, subsequent propagation was out of plane, as is predicted by linear elastic fracture mechanics. Recent experiments continue to verify the tendency for out-of-plane crack propagation when the crack is subject to a shear traction (e.g. Cooke and Pollard, 1996).

\section{The hybrid shear fracture}

Even though transitional-tensile behavior is unlikely as a mechanism for in-plane propagation of fractures subject to a shear traction, a class of fracture with dihedral angles of less than $60^{\circ}$, the hybrid shear fracture (cf. Hancock, 1985), still requires explanation. One model for hybrid shear fracture results from a stepped crack geometry (Reches and Lockner, 1994). Contours of stress intensity extend from a crack tip in a pattern that resembles a pair of rabbit ears (Fig. 4). At a given distance from a crack tip, the point of maximum stress intensity is located about $30^{\circ}$ from the plane of the crack. The line connecting these points of maximum stress intensity is known as an $M$ curve (Reches and Lockner, 1994). If two cracks are positioned such that they sit in the path of each other's $M$ curve, the pair generate a combined $M$ curve that acts on a third crack with greater normal stress than exerted by a single crack on a neighbor. Therefore, a third stepped crack in a train of en échelon cracks would be more easily dilated than the second crack. If this behavior cascades along a string of stepped cracks, a fault zone can rapidly develop.

Reches and Lockner (1994) demonstrate that the angle of a fault zone with respect to $\sigma_{1}$ is a function of crack spacing, $S$, and the crack length, $L$ (Fig. 4). They predict an angle $\theta$ between the plane of faulting and $\sigma_{1}$

$\theta=\tan ^{-1}\left\{\frac{2\left(\frac{S}{L}\right) \sin \alpha_{M}}{\sin \alpha_{M}+2\left(\frac{S}{L}\right) \cos \alpha_{M}}\right\}$

where $\alpha_{M}$ is the angle between $\sigma_{1}$ and the $M$ curve. $\theta$ may range from $0^{\circ}$ for $S / L=0$, to $34^{\circ}$ for $S / L>5$. For hybrid shear fracturing with $\theta<20^{\circ}$ (i.e. a dihedral 


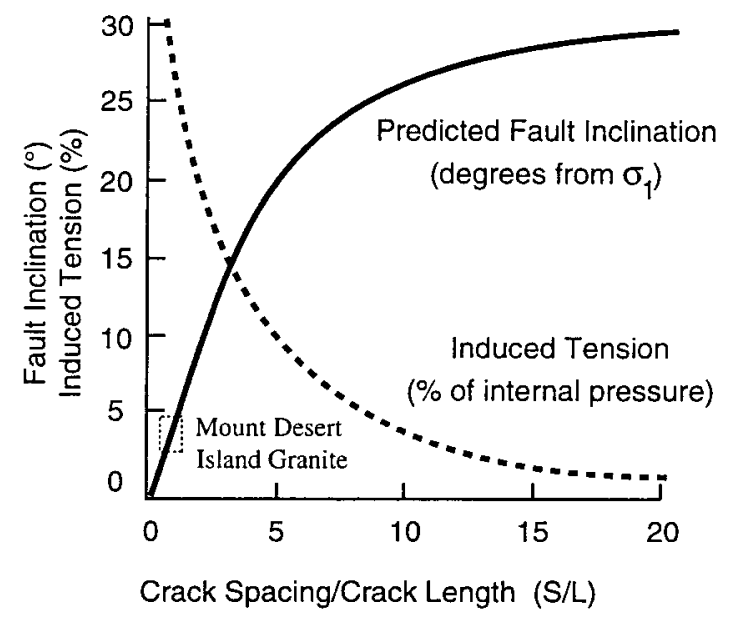

Fig. 5. Fault inclination $\theta$ (solid line) predicted by the mutual enhancement cracking model and the intensity of the induced tensile stress (dashed line) along the $M$ curve (adapted from Reches and Lockner, 1994). Data from the Mount Desert Island granite (Engelder, 1989) are plotted as a test of the stepped-crack theory for the development of hybrid shear fractures.

angle of $\left.40^{\circ}\right), S / L<0.5$. Fractures with this ratio are found in granite (Engelder, 1989).

Granites such as those of New England fracture in a series of congruent steps several $\mathrm{mm}$ to $2 \mathrm{~cm}$ in height and spaced $5-30 \mathrm{~cm}$ apart (Engelder, 1989). Treads of these steps are indistinguishable from the spectrum of relatively smooth surfaces characteristic of joints. Each step makes the same angle with the plane of the host fracture. In a cross-section through the host fracture, these steps have the form of en échelon cracks, and in three dimensions, this step-like morphology has the characteristic of a fault with pinnate joints. In some instances, the pinnate joints have opened slightly to give a visible shear offset to the host fracture. Within the Mount Desert Island granite, Maine, the angle, $\theta$, between stepped cracks and fault varies from as little as $3^{\circ}$ on some faults to as much as $18^{\circ}$. These faults qualify as hybrid shear fractures as defined by Hancock (1985).

For the hybrid shear fractures of the Mount Desert Island granite, the ratio, $S / L$, can be as low as 0.066 (Fig. 5). This ratio gives a fault inclination of about $3.5^{\circ}$ as predicted from the theory of Reches and Lockner (1994). Unlike the parabolic Coulomb-Mohr envelope, the stepped-crack model is consistent with the development of hybrid shear fracture and suitable for predicting the angle between fault zone and $\sigma_{1}$. The disadvantage of this model is the lack of any direct correlation between the angle of faulting and absolute stress or stress difference. The angle of faulting is dictated by the ratio, $S / L$.

\section{Conclusions}

The score card on validating transitional-tensile fracture propagation in an isotropic, homogeneous rock is discouraging. The appropriate theory (i.e. linear elastic fracture mechanics) predicts that it does not happen. The laboratory tests of Brace (1964), which have been traditionally cited as verification for the transitional-tensile model, offer little hope that these structures can be produced in the laboratory. Traditional field examples of transitional-tensile fracture propagation (i.e. conjugate joint sets of low dihedral angle) are now mapped as multiple jointing events. Petrofabric evidence (i.e. shear offset across veins) cannot unambiguously indicate initial in-plane propagation of a crack subject to a shear couple, as is required by the transitional-tensile model. Despite these caveats, transitional-tensile behavior does remain a viable description for the growth of veins with oblique fibers, but these are fractures guided by a strong anisotropy.

The case for hybrid shear fracturing is robust as long as it is understood that such fractures arise from the interaction of stepped cracks, as also happens during conventional shear fracturing at dihedral angles of about $60^{\circ}$. However, there appears to be no universal failure criterion for predicting the angle of faulting for hybrid shear fractures in the tensile field of the Mohr diagram. This result is different from the case for shear fracturing in the compressional field, where the Coulomb-Mohr envelope appears to be effective as a first-order estimation of faulting angle. Despite its inability to predict the angle of faulting, the CoulombMohr envelope is still a valid predictor of failure stress in the tensile field, as shown by Brace's experiments (Brace, 1964).

In summary, reference to the parabolic portion of the Coulomb-Mohr envelope over the tensile portion of the normal-stress axis is ill-advised for prediction of fracture propagation by the transitional-tensile model. If crack-seal veins with oblique fibers remain as candidates for transitional-tensile fracturing, they may be cracks guided by an inhomogeneous, anisotropic material, a process much different from that expressed by Coulomb-Mohr failure.

\section{Acknowledgements}

This work was supported by Penn State's Seal Evaluation Consortium (SEC) and the United StatesIsrael Binational Science Foundation Grant No. 9400396. Discussions with Don Fisher are appreciated. Kelly Rust, Bill Dunne, and Charlie Onash kindly reviewed earlier versions of this paper. 


\section{References}

Bahat, D., 1991. Tectonofractography. Elsevier, Amsterdam.

Brace, W.F., 1960. An extension of the Griffith theory of fracture to rocks. Journal of Geophysical Research 65, 3477-3480.

Brace, W.F., 1964. Brittle fracture of rocks. In: Judd, W.R (Ed.), State of Stress in the Earth's Crust. American Elsevier, New York, pp. 111-180.

Brace, W.F., Bombolakis, E.G., 1963. A note on brittle crack growth in compression. Journal of Geophysical Research 68, 3709-3713.

Cooke, M.L., Pollard, D.D., 1996. Fracture propagation paths under mixed mode loading within rectangular blocks of polymethyl methacrylate. Journal of Geophysical Research 101, 3387-3400.

Cox, S.F., 1987. Antitaxial crack-seal vein microstructures and their relationship to displacement paths. Journal of Structural Geology 9, 779-787.

Cruikshank, K.M., Zhao, G., Johnson, A.M., 1991. Analysis of minor fractures associated with joints and faulted joints. Journal of Structural Geology 13, 865-886.

Davis, G.H., Reynolds, S.J., 1996. Structural Geology of Rocks and Regions. John Wiley, New York.

Dennis, J.G., 1972. Structural Geology. Ronald Press, New York.

Engelder, T., 1989. The analysis of pinnate joints in the Mount Desert Island Granite: Implications for post-intrusion kinematics in the coastal volcanic belt, Maine. Geology 17, 564-567.

Erdogan, F., Sih, G.C., 1963. On the crack extension in plates under plane loading and transverse shear. Journal of Basic Engineering 85, 519-527.

Griffith, A.A., 1924. Theory of rupture. In: Proceedings of the First International Congress of Applied Mechanics, Delft, pp. 55-63.

Griggs, D.T., Handin, J. (Eds.), 1960. Rock Deformation. Geological Society of America Memoir 79.

Hancock, P.L., 1985. Brittle microtectonics: principles and practice. Journal of Structural Geology 7, 437-457.

Hancock, P.L., 1986. Joint spectra. In: Nichol, I., Nesbitt, R.W. (Eds.), Geology in the Real World-the Kingsley Dunham Volume. Institution of Mining and Metallurgy, London, pp. 155164.

Handin, J., 1969. On the Coulomb-Mohr Failure Criterion. Journal of Geophysical Research 74, 5343-5348.

Handin, J., Hager, R.V., 1957. Experimental deformation of sedimentary rocks under confining pressure: Tests at room temperature on dry samples. Bulletin of the American Association Petroleum Geologists 41, 1-50.

Hatcher, R.D., 1990. Structural Geology: Principles, Concepts, and Problems, 2nd ed. Prentice-Hall, Englewood Cliffs, New Jersey.

Hobbs, B.E., Means, W.D., Williams, P.F., 1976. An Outline of Structural Geology. John Wiley, New York.

Hoek, E., Bray, J., 1981. Rock Slope Engineering, 3rd ed. Published for the Institution of Mining and Metallurgy by. E\&FN, New York.

Hussain, M.A., Pu, S.L., Underwood, J., 1974. Strain energy release rate for a crack under combined mode I and mode II. In: Paris, P.C., Irwin, G.R. (Eds.), Fracture Analysis, Proceedings of the 1973 National Symposium on Fracture Mechanics, Part II. American Society for Testing and Materials, Special Technical Publication 560, pp. 2-28.

Ingraffea, A.R., 1987. Theory of crack initiation and propagation in rock. In: Atkinson, B (Ed.), Fracture Mechanics of Rock. Academic Press, London, pp. 71-110.

Jaeger, J.C., Cook, N.G.W., 1969. Fundamentals of Rock Mechanics. Methuen, London.

Lawn, B., 1993. Fracture of Brittle Solids, 2nd ed. Cambridge University Press, Cambridge.

Leon, A., 1934. Über die Rolle des Trennbruches im Rahmen der Mohrschen Anstrengungshypothese. Der Bauingenieur 31/32, 318-321.

Muehlberger, W.R., 1961. Conjugate joint sets of small dihedral angle. Journal of Geology 69, 211-219.

Muller, O.H., Pollard, D.D., 1977. The stress state near Spanish Peaks, Colorado determined from a dike pattern. Pure and Applied Geophysics 115, 69-86.

Murrell, S.A.F., 1958. The strength of coal under triaxial compression. In: Walton, W.H (Ed.), Mechanical Properties of NonMetallic Brittle Materials. Butterworths Scientific, London, pp. $123-146$.

Nadai, A., 1950. Theory of Flow and Fracture of Solids. McGrawHill, New York.

Olson, J.E., Pollard, D.D., 1989. Inferring paleostress from natural fracture patterns: A new method. Geology 17, 345-348.

Parker, J.M., 1942. Regional systematic jointing in slightly deformed sedimentary rocks. Geological Society of America Bulletin 53, 381-408.

Paterson, M.S., 1978. Experimental Rock Deformation-The Brittle Field. Springer-Verlag, New York.

Pollard, D.D., Segall, P., 1987. Theoretical displacements and stresses near fractures in rock: with applications to faults, joints, veins, dikes, and solution surfaces. In: Atkinson, B (Ed.), Fracture Mechanics of Rock. Academic Press, Orlando, pp. 227350.

Price, N.J., 1958. A study of rock properties in conditions of triaxial stress. In: Walton, W.H (Ed.), Mechanical Properties of NonMetallic Brittle Materials. Butterworths Scientific, London, pp. $106-122$.

Price, N.J., Cosgrove, J.W., 1990. Analysis of Geological Structures. Cambridge University Press, Cambridge.

Reches, Z., Lockner, D., 1994. Nucleation and growth of faults in brittle rocks. Journal of Geophysical Research 99, 18159-18174.

Sih, G.C., MacDonald, B., 1974. Fracture mechanics applied to engineering problems-strain energy density fracture criterion. Engineering Fracture Mechanics 6, 361-386.

Suppe, J., 1985. Principles of Structural Geology. Prentice-Hall, Englewood Cliffs, New Jersey.

Twiss, R.J., Moores, E.M., 1992. Structural Geology. W.H Freeman, New York.

van der Pluijm, B.A., Marshak, S., 1997. Earth Structure: An Introduction to Structural Geology and Tectonics. McGraw-Hill, New York

Younes, A., Engelder, T., 1999. Fringe cracks: Key structures for the interpretation of progressive Alleghanian deformation of the Appalachian Plateau. Geological Society of America Bulletin 111, 219-239.

Ziony, J.I., 1966. Analysis of systematic jointing in part of the Monument Upward, southwestern Utah. PhD thesis, Los Angeles, University of California at Los Angeles, 152 pp. 